\title{
Dentigerous Cyst with Ectopic Tooth in Maxillary Sinus of A Child - A Rare Occurrence
}

Dimple Sahni ${ }^{1}$

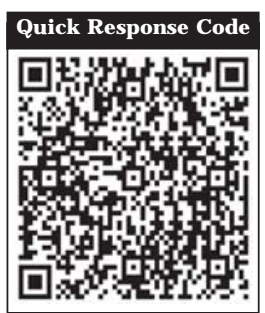

doi: $10.5866 / 2014.641717$

${ }^{1}$ Assistant Professor

Department of ENT,

Govt. Medical College, Patiala.

\section{Article Info:}

Received: J uly 10, 2014

Review Completed: August 9, 2014

Accepted: November 8, 2014

Available Online: J anuary, 2015 (www.nacd.in)

(C) NAD, 2015 - All rights reserved

Email for correspondence:

sawhneygirish@gmail.com

\begin{abstract}
:
An ectopically erupted tooth with infected dentigerous cyst within the maxillary sinus of a child is a rare occurrence. $A$ twelveyear old malechild presented with rhinorrhoea, haliotosis and swelling over the right cheek. It was diagnosed to bea large dentigerous cyst with ectopic tooth and right maxillary sinus. However it is a rare entity in children, commonly occur in mandible of middleaged persons. Early diagnosis and treatment is an essential as it has greater tendency to produce some resorption of other teeth as compare to other jaw cyst. Although marsupialization is treatment of choice in children but in the present case the cyst had lined the antral cavity hence enudeation had to be done through caldwell luc approach.
\end{abstract}

Key words: Dentigerous cyst, maxillary sinus ectopic tooth eruption, Caldwell luc approach.

\section{INTRODUCTION}

A dentigenous cyst is defined as a cyst which envelops the whole or a part of crown of unerrupted tooth and is attached to its neck (amelocemental junction). ${ }^{1}$ Many theories have been put forward as regard to origin of dentigerous cyst. However strongest contention is that the cyst originates from reduced enamel epithelium as epithelial lining is attached to the neck of tooth. Most often involved tooth is mandibular $3^{\text {rd }}$ molar. ${ }^{2}$ Rarely a tooth or root may be present within the sinus cavity and may be associated with dentigerous cyst around it. ${ }^{3}$ An ectopically erupted tooth with dentigerous cyst in maxillary sinus present as maxillary sinusitis.

\section{Case Report}

A 12 years old male child had rhinitis since five months for which he took treatment from registered medical practitioner and was not relieved. In the mean time swelling appeared on the right cheek and discharge started coming out from upper tooth. He then came to ENT department, Rajindra Hospital, Patiala. 
Examination revealed right maxillary swelling measuring about $3 \times 3 \mathrm{~cm}$ with mild tenderness. The swelling had encroached upon the right alveolar process and fixed to the maxilla. Complete haemogram and urine examination was done. TLC was $12000 / \mathrm{cmm}$ with raised neutrophils.

X-ray PNS water's view showed air fluid level in the maxillary sinus (Figure 1). CT scan showed dentigerous cyst with ectopic tooth in the right maxillary sinus (Figure 2).

\section{Treatment}

Cald-Well-Luc operation was done on right side under general anaesthesia. Gush of pus came out of the antrum, which was sent for culture sensitivity. The tooth loosely adherent in the postero-superior wall of the right maxillary antrum was extracted out. Antrum was washed with betadine and packed with roller gauze impregnated with Neosporin ointment. Haemostasis was achieved and wound closed. Pack was removed after 24 hours and the patient was discharged in satisfactory condition with postoperative period uneventful.

\section{Discussion}

Dentigerous cyst are most frequent type of developmental odontogenic cyst derived from epithelial remnants of tooth forming organs. ${ }^{4} \mathrm{M}$ any different factors are involved in the development of these cysts. There are two different views which are the congenital anomaly view and the stimulatory view by inflammation. ${ }^{5}$

The cyst develops by accumulation of fluid between the reduced enamel epithelium and the enamel or between the layers of reduced enamel epithelium. The tooth is displaced deep into the jaw and prevented from errupting by the cyst.

The cyst has an internal epithelial lining and an outer dense fibrous tissue covering. The lining epithelium is non keratinised stratified squamous. The cyst contains fluid or semi-fluid content with cholesterol crystals and giant cells.

Dentigerous cyst constitute about $24 \%$ of all jaw cysts. ${ }^{5}$ They occur at any age but the highest incidence is in third and fourth decade. ${ }^{6}$ They are

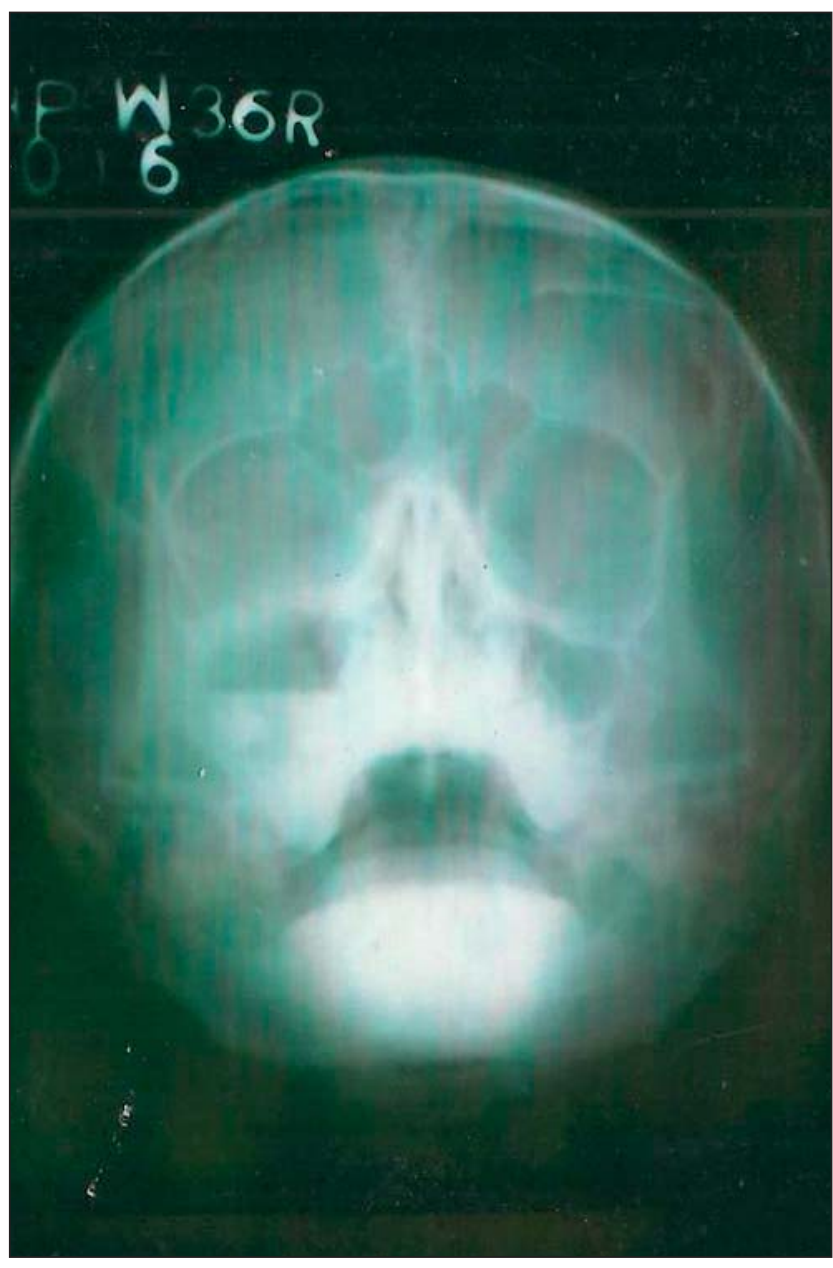

Figure 1: PNS water's view showing air fluid level in the maxillary sinus.

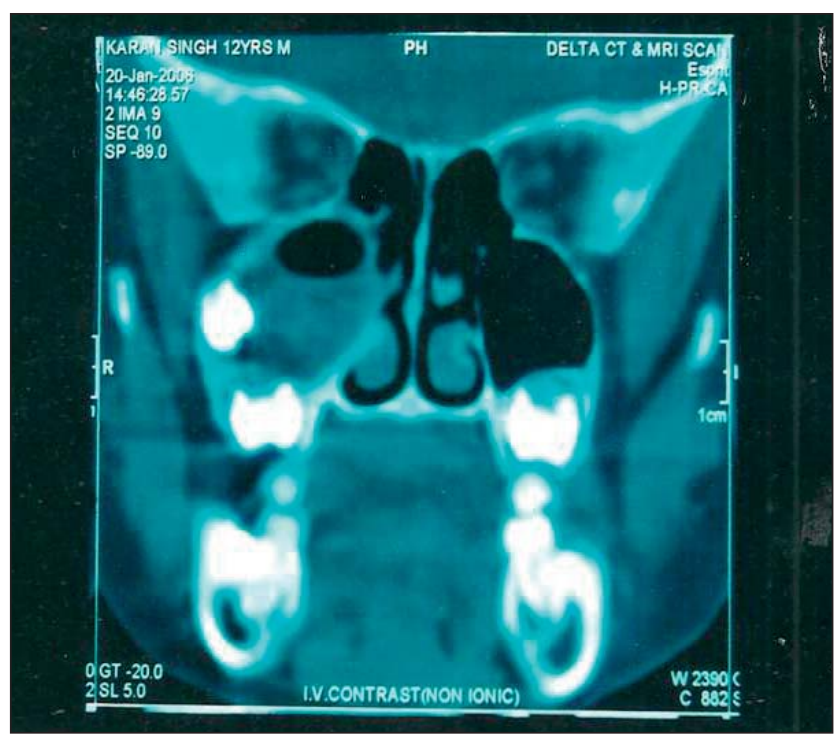

Figure 2: CT scan showing dentigerous cyst with ectopic tooth in the right maxillary sinus. 
much more common in men than women ratio being 1.84:1 and five times more likely to occur in white population than black. ${ }^{7}$

They most commonly involve third molar of the mandible and then in decreasing frequency the maxillary canine, mandibular premolar and maxillary third molar. Prevalence of mandibular cyst is twice more common than maxillary cyst. ${ }^{8}$ Generally these cyst are painless remain dormant though may cause some expansion of cortical bone. ${ }^{9}$ If it gets infected inflammatory symptoms likefacial pain swelling and sensory changes occur. Formation of fistula can occur when dentigerous cyst in maxillary sinus present as sinusitis with purulent discharge. ${ }^{10}$

Rarely, it may show neoplastic transformation ameloblastoma and sqamous cell carcinoma. Some intra osseus muco epidermioid carcinoma develop from mucous cells in the lining of dentigerous cyst. ${ }^{11}$

CT scan is gold standard investigation in diagnosis of paranasal sinus pathology. There were two modalities of treatment either by enucleation or marsupialisation. In our case to prevent moroantral histoloformation removal of tooth was done via caldwell luc approach. ${ }^{12}$

\section{Conclusion}

Infected dentigerous cyst with ectopic tooth in the night maxillary sinus of a child is a rare occurrence. Such cysts should be managed by excision as soon as possible. My patient presented with history of rhinorrhoea, halio tosis and swelling over the right cheek. After radiological diagnosis investigation it was diagnosed to the dentigerous cyst associated with an ectopic tooth in the right maxillary sinus. Enucleation of the cyst with removal of the tooth was carried out via Caldwell luc approach. The recovery was uneventful.

\section{Reference}

1. Scott-Brown's otolaryngol ogy $6^{\text {th }}$ edition 1997: Butter WorthHeinemann 5/23/5-6.

2. Neville BW, Dam DD, Allen CM, Bouquet J E. Oral and maxillofacial pathology. $2^{\text {nd }}$ edn. Saunders; C2001; 768.

3. Srinivasa PT, Sujatha G, Thanvir MN, Rajesh $P$. Dentigerous cyst associated with an ectopic third molar in the maxillary sinus. A rare entity. Indian J Dent Res 2007; 18(3):141-143.

4. Amin ZA. Amran M, Khairudin. Removal of extensive maxillary dentigerous cyst via a Caldwell-Luc procedure. Arch Orofac Sci 2008; 3(2):48-51.

5. Soon J ae Hwang, Heung-Man Lee, Dae Hyung Kim, Dong J in Lee, J ang Hyeog Lee, J in Ho Choi, Sang Hag Lee, Dentigerous cyst involving the maxillary sinus. J Rhinol 2001; 8(1,2):54-57.

6. Mervin S and Paul SM. Cysts of the oral cavity and maxillofacial regions. $4^{\text {th }}$ edn. Blackwell Munksgaard Publishers; c2007; 228.

7. Shera M. Cyst of the oral regions $3^{\text {rd }}$ edn. Bristol Weight. 1992.

8. Kumar RM, Umashankar DN, Nandakumar H, Bawle MR, Sudhakar. Inflammatory variant of dentigerous cyst in maxillary sinus - a case report. Int J Oral Maxillofac Pathol 2010; 1(1):17-19.

9. Smith G, Smith AJ, Browne RM. Histochemical studies on glycosaminoglycons of odontogenic cyst. J ournal of Oral Pathology 1988; 17:55-59.

10. Albert SP. Dentigerous cyst in maxillary sinus. J Natl Med Assoc 1970; 62(9):453-454.

11. Saraf S. Cyst of oral and paraoral structures. Textbook of oral pathology 2006; 209-211.

12. Goh YH. Ectopic Eruption of Maxillary Molar Tooth-An Unusual Cause of Recurrent Sinusitis. Singapore Med J 2001; 42(2):80-81.

\section{Gain quick access to our journal online View our journal at www.nacd.in}

